\title{
Barodontalgia: A Study on its Etiology in Saudi Population Muhammed Ajmal ${ }^{1 *}$, Shomokh A Abu-Msmar ${ }^{2}$, Lamia A. Alkodari², Roaa M. Aseeri ${ }^{2}$ Bashaier H. Alshehri ${ }^{2}$
}

${ }^{1 *}$ Assistant Professor, Dept. Diagnostic Sciences, College of Dentistry, King Khalid University, Abha, Saudi Arabia. ${ }^{2}$ Interns, College of Dentistry, King Khalid University, Abha, Saudi Arabia. drmajmal@gmail.com

*Corresponding Author: Dr. Muhammed Ajmal, Assistant Professor, Dept. Diagnostic Sciences, College of Dentistry, King Khalid University, Abha, Saudi Arabia.

\section{Abstract}

Aim: To study the etiology of Barodontalgia in Saudi population.

Methods: A total of 369 individuals having dental restorations and a history of flight journey were randomly selected for the study. A questionnaire was used to collect general data such as age, gender; flight experience and a specific set of questions related to pain during flight and dental risk factors such as dental caries, dental restorations and pre existing dental pain conditions were given to all participants. Those patients affected by barodontalgia were further subjected to a personal interview and clinical examination for identification of dental risk factors. The data was collected and statistical analysis was made. Because of the descriptive nature of the study, no adjustments after multiple comparisons were made.

Results: The study sample included 241 females and 128 males. Out of the 369 individuals, 59 patients reported tooth pain during flight and nearly 50\% of these cases reported pain during the middle of the flight. Around $55 \%$ of patients had an existing restoration in the tooth, 28.8 cases \% with dental caries, $12.8 \%$ cases with periapical abscess, and $25 \%$ of them had pre existing migraine headache. The pain was of throbbing type and the duration of pain lasted for few seconds in about $79 \%$ of the cases and throughout the entire flight in $21 \%$ of these cases.

Conclusion: A good number of participants in our study presented with barodontalgia. This phenomenon is found to be reported frequently due to an increase in air travellers in recent times and resultant dental barotraumas can cause significant morbidity necessitating special precautions to prevent any kind of in-flight incapabilities that can potentially endanger lives. It is therefore important for all allied personnel such as aircraft crew, family dentists, etc be aware of this phenomemon and initiate appropriate preventive measures to reduce complications.

Keywords: Barodontalgia,Barotrauma, Periapical Pathologies, Restorations

\section{INTRODUCTION}

Barodontalgia is the term used to describe tooth pain occurring due to variations in Environmental pressure (barometric pressure). Barodontalgia was first observed among air crew during World War II and was initially given the name "aerodontalgia" It was later discovered among deep sea divers too and a large number of personnel working in hyperbaric environment such as pilots, divers, submariners and hyperbaric oxygen therapy report with split teeth, displaced restorations and pain probably attributable to dental barotraumas.

Barotrauma is the pressure-induced damages that occur at high and low pressures and is best explained with relation to Boyle's law. Boyle's law states that the volume of a fixed mass of an ideal gas is inversely proportional to the pressure of the gas at constant temperature. These volumetric pressure changes in gas -filled cavities (Lungs, Middle ear Paranasal Sinus) lead to barotraumas, clinically resulting in pain, 
oedema, or vascular gas embolism. ${ }^{1-3}$

Barotraumas in the orofacial area include barotitis media, barosinusitis, pressure-induced headache, barodontalgias, and dental barotraumas. Dental barotraumas are defined as pressure induced damages to the teeth and dental restorations whereas barodontalgia is referred to as intraoral pain elicited by changes in pressure. ${ }^{4}$ Barosinusitis (Barotrauma of the maxillary sinus) causes headaches, numbness and /or dental pain in the region of the maxillary posterior teeth. Clinically it is difficult to differentiate between barosinusitis and barodontalgia on the basis of maxillary teeth pain alone. It is reported that dental pain occurring during ascent is suggestive of non vital pulp tissue (pulpitis), whereas dental pain during descent can be either due to pulp necrosis or facial barotraumas.

The reported incidence of barodontalgias is 0.26-2.8\% among aircraft personnel, air passengers, and divers. Barodontalgia is reported to occur at flying altitudes of 600-1500m and at diving depths of $10-25 \mathrm{~m}^{5-9}$

The exact mechanism that causes pain in barodontalgia is not clear, except for the exposure to altered atmospheric pressure. It is postulated that changes in pressure acts as a precipitating factor, in a tooth with pre existing pulpal/periapical disease \&/ or dental restorations. ${ }^{6-7}$ Some authors believe that barodontalgia can occur in apparently healthy teeth when the alterations in pressure is atleast 3 levels of atmospheric pressure, ${ }^{10}$ whereas few authors suggest that teeth with normal pulp is not associated with pain irrespective of the presence of restorations or caries. ${ }^{11}$

Barodontalgia is broadly categorised into direct and indirect types. The direct type is well localised and occurs when reduced atmospheric pressure directly affects the tooth resulting in moderate to severe pain, usually during ascent, whereas the indirect type is characterised by dental pain secondary to stimulation of the superior alveolar nerves by maxillary barosin usitis resulting in dull, poorly defined pain during descent that generally involves the posterior maxillary teeth. $^{12}$
The pain associated with barodontalgia can be severe enough to affect the health and ability of the personnel to apply them at work (especially associated with high risk), endangering the life of the personnel as well as other individuals such as aircraft with crew or passengers. $^{13-14}$

The present study was conducted to find plausible dental risk factors of barodontalgia by evaluating dental and orofacial symptoms in individuals exposed to pressure changes using questionnaires and personal interviews.

\section{MATERIAls ANd Methods}

A total of 369 individuals (241 were females and 128 were males) having dental restorations and a history of flight journey were randomly selected for the study.

A questionnaire was used to collect general data such as age, gender; flight experience and a specific set of questions related to pain during flight and dental risk factors such as dental caries, dental restorations and pre existing dental pain conditions were given to all participants. Those patients affected by barodontalgia were further subjected to a personal interview and clinical examination for identification of dental risk factors.

The data was collected and statistical analysis was made. Because of the descriptive nature of the study, no adjustments after multiple comparisons were made.

\section{RESULTS}

The study sample included 241 females and 128 males. Out of the 369 individuals, 59 patients reported tooth pain during flight and nearly $50 \%$ of these cases reported pain during the middle of the flight. approximately 55\% of these 59 patients had an existing restoration in the tooth, 28.8 cases \% had dental caries, $12.8 \%$ cases presented with periapical abscess, and $25 \%$ of them had an account of pre existing migraine headache. The reported pain was of throbbing in type lasting for few seconds in about $79 \%$ of the reported cases and throughout the entire flight in $21 \%$ of these cases. (Table 1 \&2) 


\section{Barodontalgia: A Study on its Etiology in Saudi Population}

Table 1. Questionnaire data of the study group

\begin{tabular}{|c|c|c|c|}
\hline Questions & Response & Questions & Response \\
\hline \multirow[t]{2}{*}{ Did you have tooth pain while boarding the plane? } & \multirow[t]{2}{*}{$\begin{array}{l}\text { Yes: } 16 \% \\
\text { No: } 84 \%\end{array}$} & What was the duration of pain & \\
\hline & & Forfew seconds & $79 \%$ \\
\hline \multicolumn{2}{|l|}{ If yes, what do you think the reason for pain } & During the entire flight & $21 \%$ \\
\hline Tooth decay & $28.8 \%$ & & \\
\hline Tooth abscess & $12.8 \%$ & Do you have any systemic diseases? & \\
\hline \multirow[t]{2}{*}{ Tooth was RCT treated } & \multirow[t]{2}{*}{$28.7 \%$} & & \\
\hline & & Migraine & $25 \%$ \\
\hline Tooth had filling & $26.6 \%$ & Hypertension & $8.8 \%$ \\
\hline Tooth was fine & $19.1 \%$ & Heart disease & $7.5 \%$ \\
\hline When the pain started & \multirow[b]{2}{*}{$12.4 \%$} & Others & $26.3 \%$ \\
\hline - During take off & & Healthy & $32.5 \%$ \\
\hline \multirow[t]{2}{*}{ During landing } & \multirow[t]{2}{*}{$38.2 \%$} & & \\
\hline & & Total sample & 369 \\
\hline \multirow{2}{*}{ During middle of the flight } & \multirow{2}{*}{$49.4 \%$} & Male & 128 \\
\hline & & Female & 241 \\
\hline
\end{tabular}

Table 2. Clinical findings of Barodontalgia patients

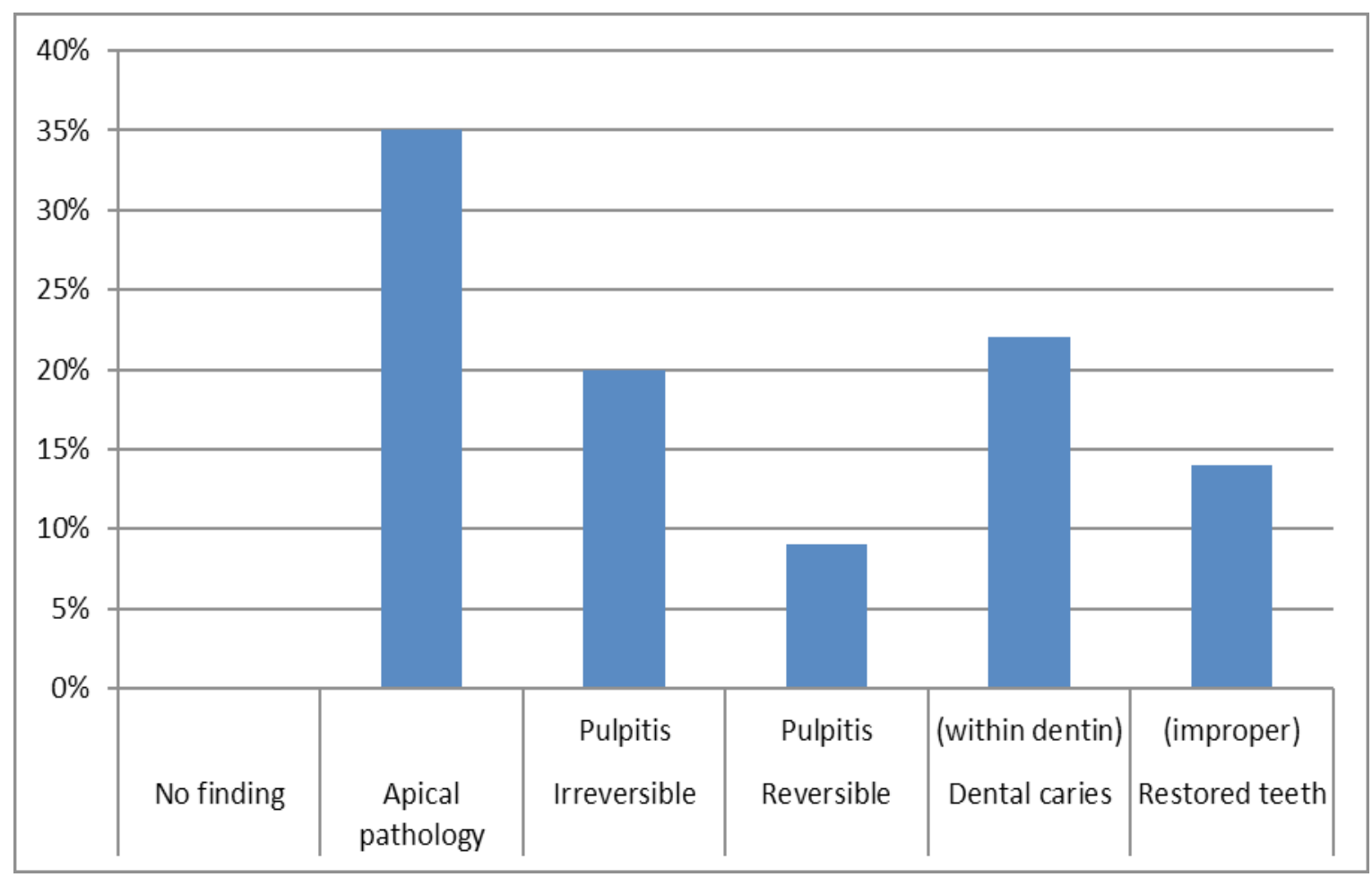




\section{DISCUSSION}

Barodontalgia is the term used to describe tooth pain occurring due to variations in Environmental pressure (barometric pressure) in otherwise healthy individuals.Barodontalgia is considered to be a flareup symptom of pre-existing subclinical oral disease such as dental caries with or without pulp involvement, faulty dental restorations,periapical pathologies ${ }^{5,14-16}$

The present study was conducted to find plausible dental risk factors of barodontalgia by evaluating dental and orofacial symptoms in individuals exposed to pressure changes using questionnaires and personal interviews.In our study, barodontalgia was reported in 55\% of patients with an existing restoration in the tooth followed by 28.8 cases \% with dental caries and $12.8 \%$ cases with periapical pathologies. Indirect referred pain was reported in $25 \%$ of patients who had pre existing migraine headache.

Our findings are similar to that of studies by kollman ${ }^{5}$ who in a high altitude simulation series reported tooth pain in pre existing restored teeth(36\%) and periapical pathologies $(14 \%)^{5}$ and by Zadik Y et al ${ }^{6}$ who reported barodontalgia in restored teeth (29.6\%) followed by periapical pathologies(18.5\%) and barosinusitis (18.5\%) whereas in a study by GonzalezSantiago Mdel et al ${ }^{9}$, the incidence of barodontalgia in teeth with periapical pathologies was $39 \%$ and $23 \%$ in faulty restorations.

The reported incidence of barodontalgias is $0.26-2.8 \%$ among aircraft personnel, air passengers, and divers. Barodontalgia is reported to occur at flying altitudes of $600-1500 \mathrm{~m}$ and at diving depths of $10-25 \mathrm{~m} .^{5-9}$

Various theories have been suggested to describe the poorly understood mechanism causing barodontalgia Pulpal ischemia \&/or elevated intracanal gas gas pressure is believed to be the underlyng mechanism causing barodontalgia in a tooth with dental caries with inflamed pulp. ${ }^{15,17,18,19}$ However, this fails to explain the cause of barodontalgia in periapical pathologies and elevated pressure within the bony lesion is reasoned as the cause for barometric changes and pain in such cases. ${ }^{14}$

Cases of dental barotraumas such as pressure induced fractures of dental teeth, dental restoration, vertical root fracture in endodontically treatment teeth have been reported in literature. ${ }^{20}$ These complications and the morbidity that is associated with pain due to barodontalgia can be severe enough to affect the health and ability of the personnel to effectively engage at work (especially associated with high risk), endangering the life of the personnel as well as other individuals such as aircraft with crew or passengers. It is therefore important for all allied personnel such as aircraft crew, family dentists, etc be aware of this phenomemon and initiate appropriate preventive measures to reduce complications.

Our study was restricted to a limited sample of aircraft passengers and further studies with larger samples involving aircraft personnel, divers, etc needs to be done to better understand this phenomenon.

\section{ConCLUSION}

A good number of participants in our study presented with barodontalgia. This phenomenon is found to be reported frequently due to an increase in air travellers in recent times and resultant dental barotraumas can cause significant morbidity necessitating special precautions to prevent any kind of in-flight incapabilities that can potentially endanger lives. It is therefore important for all allied personnel such as aircraft crew, family dentists, etc be aware of this phenomemon and initiate appropriate preventive measures to reduce complications.

\section{REFERENCES}

[1] M. Hamilton-Farrell and A. Bhattacharyya. Baro trauma. Injury. 2004 Apr;35(4):359-70

[2] J. Kieser. Sinus barotrauma presenting as acute dental pain. South African Medical Journal 1997; 87(2):184.

[3] J. Kressin. Aviation medicine problems in otorhinolaryngology. Zeitschrift Fur Arztliche Fortbildung Und Qualitatssicherung 1999; 93(7) :509-512.

[4] Zadik Y, Drucker S: Diving dentistry: a review of the dental implications of scuba diving. Aust Dent J 2011; 56: 265-271.

[5] W. Kollmann. Incidence and possible causes of dental pain during simulated high altitude flights. Journal of Endodontics 1993; 19(3):154-159.

[6] Y. Zadik, L. Chapnik, and L. Goldstein. In-flight barodontalgia: analysis of 29 cases in military aircrew. Aviation Space and Environmental Medicine 2007; 78(6):593-596.

[7] Y. Zadik, "Barodontalgia," Journal of Endo dotics .2009; 35(4):481-485. 
[8] D. M. Taylor, K. S. O’Toole, and C. M. Ryan, "Experienced scuba divers in Australia and the United States suffer considerable injury and morbidity," Wilderness and Environmental Medi cine.2003; 14(2):83-88.

[9] M. Del Mar Gonz'alez Santiago, A. MartinezSahuquillo Marquez, and P. Bull 'on Fern'andez, "Incidence of barodontalgias and their relation to oral/dental condition in personnel with responsibility in military flight," Medicina Oral .2004; 9(2):92-105.

[10] Hodges FR. Barodontalgia at 12,000 feet. J Am Dent Assoc 1978; 97: 66-73.

[11] Ferjentsik E, Aker F. Barodontalgia: a system of classification. Milit Med 1982; 147: 303-4.

[12] Strohaver RA. Aerodontalgia: dental pain during flight. Med Serv Dig 1972; 23: 35-41

[13] Jagger RG, Jackson SJ, Jagger DC. In at the deep end - an insight into scuba diving and related dental problems for the GDP. BrDent J.1997; 183:380-382.
[14] Zadik Y. Barodontalgia due to odontogenic inflammation in the jawbone. Aviat Space Environ Med 2006; 77:864-866.

[15] Kennebeck R, Knudtzon KF, Goldhush AA, et al. Symposium on problems of aviation dentistry. J Am Dent Assoc 1946; 33:827-44.

[16] Senia ES, Cunningham KW, Marx RE. The diag nostic dilemma of barodontalgia: report of two cases. Oral Surg Oral Med Oral Pathol 1985; 60 :212-7.

[17] Harvey W. Dental pain while flying or during decompression tests. Br Dent J 1947; 82:113- 8.

[18] Levy BM. Aviation dentistry. Am J Orthodont Oral Surg 1943; 29:92-5.

[19] Orban B, Ritchey BT. Toothache under conditions stimulating high altitude flight. J Am Dent Assoc 1945 ; 32:145- 80 .

[20] Zadik Y, Einy S, Pokroy R, et al. Dental fractures on acute exposure to high altitude. Aviat Space Environ Med 2006; 77:654 -7.

Citation: Muhammed Ajmal, Shomokh A Abu-Msmar, Lamia A. Alkodari, Roaa M. Aseeri, Bashaier H. Alshehri. Barodontalgia: A Study on its Etiology in Saudi Population. Archives of Dentistry and Oral Health. 2018; 1(2): 32-36.

Copyright: (C) 2018 Muhammed Ajmal, Shomokh A Abu-Msmar, Lamia A. Alkodari, Roaa M. Aseeri, Bashaier H. Alshehri. This is an open access article distributed under the Creative Commons Attribution License, which permits unrestricted use, distribution, and reproduction in any medium, provided the original work is properly cited. 